\title{
The Complications of Controlling Agency Time Discretion: FDA Review Deadlines and Postmarket Drug Safety
}

\section{Citation}

Carpenter, Daniel, Jacqueline Chattopadhyay, Susan Moffitt, and Clayton Nall. 2011. "The Complications of Controlling Agency Time Discretion: FDA Review Deadlines and Postmarket Drug Safety." American Journal of Political Science 56 (1) (October 14): 98-114. doi:10.1111/ j.1540-5907.2011.00544.x.

\section{Published Version}

doi:10.1111/j.1540-5907.2011.00544.x

\section{Permanent link}

http://nrs.harvard.edu/urn-3:HUL.InstRepos:34796902

\section{Terms of Use}

This article was downloaded from Harvard University's DASH repository, and is made available under the terms and conditions applicable to Open Access Policy Articles, as set forth at http:// nrs.harvard.edu/urn-3:HUL.InstRepos:dash.current.terms-of-use\#OAP

\section{Share Your Story}

The Harvard community has made this article openly available.

Please share how this access benefits you. Submit a story.

Accessibility 
$<<$ AUTHOR RUNNING HEAD $>>$ Carpenter et al.

$<<$ SHORT TITLE $>>$ Agency Time Discretion and FDA Deadlines

$<<$ TITLE $>>$ The Complications of Controlling Agency Time Discretion: FDA Review

Deadlines and Postmarket Drug Safety

$<<$ AU $>>$ Daniel Carpenter

$<<\mathrm{AF}>>$ Harvard University

$<<$ AU $>>$ Jacqueline Chattopadhyay

$<<\mathrm{AF}>>$ Harvard University

$<<$ AU $>>$ Susan Moffitt

$<<$ AF $>>$ Brown University

$<<$ AU $>>$ Clayton Nall

$<<\mathrm{AF}>>$ Stanford University

$<<\mathrm{BIO}>>$ Daniel Carpenter (dcarpenter@gov.harvard.edu) is Allie S. Professor of Government, Harvard University, 1737 Cambridge Street, Cambridge, MA 02138, and (2011-2012) Visiting

Researcher, Institut d'Études Politiques, Université de Strasbourg, France. Jacqueline Chattopadhyay (jchattop@fas.harvard.edu) is Ph. D. Candidate in Government, Harvard University, 1737 Cambridge Street, Cambridge, MA 02138. Susan Moffitt

(Susan_Moffitt@brown.edu) is Mary Tefft and John Hazen White Sr. Assistant Professor of Political Science, Brown University, 36 Prospect Street, Providence, RI 02912. Clayton Nall (nall@stanford.edu) is Assistant Professor of Political Science, Stanford University, 616 Serra Street, Encina Hall West, Room 100, Stanford, CA 94305-6044.

$<<\mathrm{ACK}>>$ For critical remarks and helpful discussions, we thank Jerry Avorn, Einer Elhauge, Gary King, Bruce Psaty, Meredith Rosenthal, Katherine Swartz, Heidi Williams, the Editor and anonymous reviewers, and audiences at Harvard Medical School, Harvard Law School, the Keck Graduate Institute of Applied Life Sciences, and the Ohio State University. Carpenter acknowledges the National Science Foundation (SES-0076452 and SES-0351048), a Robert Wood Johnson Foundation Investigator Award in Health Policy Research and the Safra Center for Ethics at Harvard University. Carpenter and Moffitt also acknowledge the Robert Wood Johnson Foundation Scholars in Health Policy Research Program. All replication data and code for this article will be available on the date of publication at http://people.hmdc.harvard.edu/ dcarpent/fdaproject/deadlinesstudy2011.html. $<<$ KEYWORDS $>>$ agency time discretion, deadlines, time pressure, pharmaceuticals $<<\mathrm{AB}>>$ Public agencies have discretion on the time domain, and politicians deploy numerous policy instruments to constrain it. Yet little is known about how administrative procedures that affect timing also affect the quality of agency decisions. We examine whether administrative deadlines shape decision timing and the observed quality of decisions. Using a unique and rich dataset of FDA drug approvals that allows us to examine decision timing and quality, we find that this administrative tool induces a piling of decisions before deadlines, and these "justbefore-deadline" approvals are linked with higher rates of postmarket safety problems (market withdrawals, severe safety warnings, safety alerts). Examination of data from FDA advisory committees suggests that the deadlines may impede quality by impairing late-stage deliberation and agency risk communication. Our results both support and challenge reigning theories about administrative procedures, suggesting they embody expected control-expertise trade-offs, but may also create unanticipated constituency losses.

$<<$ text $>>$ 
Elected officials deploy a broad scope of institutional tools to influence government agencies' decisions. The proposition that political control entails trade-offs - administered policy that hews closer to the wishes of elected officials and their constituents, possibly at the expense of the decision quality that agency expertise and experimentation can bring (Bawn 1995, 63; Weingast 1984) - is often theorized but rarely tested. Various instruments of political control function to constrain bureaucratic choice (Bawn 1995; Carpenter 1996; Huber and Shipan 2002; McCubbins, Noll, and Weingast 1987, 1989; Moe 1985), but there is little evidence on whether administrative procedures shape the quality of policy outcomes that officials and citizens ultimately care about. Scholarship on agency design and appointments suggests instruments of political control bear on general agency performance (Krause and Douglas 2006; Lewis 2008; Whitford 2005) and processes (Yackee and Yackee 2010). Yet, there are few if any rigorous tests of the critical puzzle that has motivated scholarship for decades: do instruments of political control affect the quality of policy outcomes?

In this article we examine this question with a rare empirical dataset that permits simultaneous analysis of (1) a change in the imposition of a procedural requirement and (2) a metric of decision quality for analyzing the observed effects of that change. We examine FDA deadlines for drug approval and combine this data with a database on the postmarket experience of these drugs - what happens to them after they are approved. Our analysis rests on an estimated association between approval decisions made just before the deadline and a differential pattern of postmarket experience and risk. It is rare in political science to have a metric of quality that can be used to estimate the impact of any tools of political control (structure, process, budgets, personnel, qualifications restrictions on appointments, etc.) on the quality of agency decisions. Our data offer multiple measures of the quality of agency decisions.

The control of agency discretion is usually interpreted as a matter of left-right policy, or of "more" or "less" regulation (Bawn 1995; Moe 1985). Yet agencies have another domain of discretion that does not map cleanly onto the dimensions that are heavily studied: time. Agency time discretion is the abundant leeway that agencies have over when to make a decision, regardless of what that decision will be. Put differently, agencies shape policy not merely by making decisions but by waiting to decide (Ando 1999, Carpenter 2002, 2004 Whitford 2005). In other words, public agencies have the important resource of discretion on the time domain. ${ }^{1}$ The customary tools for controlling administrative discretion-budgets, appointments, and even administrative procedures associated with rulemaking-may not constrain time discretion and could even exacerbate the gap between elected officials' preferences and agency actions. To consider one obvious example, if an agency is considered too slow to act, a budget cut may worsen the problem by depriving decision makers of resources needed to speed up agency processes. Alternatively, the effects of a budget increase will depend on how resources are allocated, the elasticity of decision speed with respect to these resources, and the rapidity with which new resources are applied (Carpenter 1996; Ting 2001).

Deadlines - the combination of a target time for a decision or task and an associated penalty borne by the agent for failing to meet the target time-comprise the most common procedural tool used to constrain agency time discretion. While infrequently studied in political science, deadlines are a common feature of regulatory statutes and a common mechanism by

\footnotetext{
${ }^{1}$ We thank an anonymous reviewer for this language.
} 
which Congress attempts to control the bureaucracy (Kerwin 2003). We believe our analysis is the first to link agency decisions to the particular control tool of deadlines. ${ }^{2}$

Deadlines can be real or merely nominal constraints. Their incidence alone rarely grants scholars any ability to infer either the Congressional intent behind them or their impact on agencies. Still, if placed on a continuum of administrative tools ranging from least to most intrusive in the affairs of the bureaucracy, deadlines would almost certainly fall on the more intrusive half of the continuum. Deadlines seek to target not just any aspect of bureaucratic discretion, but the critical and neglected component of timing. ${ }^{3}$

This distinction between the content and timing of decisions is central to many debates over policy and institutions. For instance, critics from the 1970 s to the 1990 s complained not that the FDA was rejecting drugs, but that the agency was too slow to approve the drugs that it did. Time may translate into a number of processes and variables of interest in institutional political science - not only information gathering, but also reflection, deliberation, and consultation, and procedural thoroughness (Abbott 1987; Krause 2003; Spence 1999; Yackee and Yackee 2010). Legislators themselves have expressed concern about a potential trade-off between decision speed and quality and about the potential adverse impact of the lack of Congressional expertise in setting timelines. ${ }^{4}$

Our analyses of the FDA imply a causal association between just-before-deadline decisions and reduced decision quality. We examine a range of outcome variables capturing postmarket events (PMREs) — whether the drug was withdrawn, whether it experienced major labeling revisions, whether the FDA had to issue safety alerts for the drug after approval and others. Furthermore, through use of nonparametric matching techniques in our supplemental analyses, we are able to suggest the magnitude of a causal effect while allowing for the usual caveats about observational causal inference. Additionally, while not our central focus, analysis of associated health and medical data suggests that these postmarket events are associated with tens of thousands of additional hospitalizations, adverse drug reactions, and deaths. Through the use of data on advisory committee meetings, we also suggest that the mechanism behind our findings may reside in the final stages of the approval process, if labeling and risk management strategies for approved drugs receive short shrift in the face of looming deadlines.

Our purposes and analyses here thus differ substantially from those in a related article (Carpenter, Zucker, and Avorn 2008), which has provoked debate among political scientists and FDA officials (see Nardinelli et al. 2008). Our interest here is squarely upon what an analysis of deadlines at the FDA suggests for scholarship on political control of the bureaucracy. ${ }^{5}$

Though the finding of an association between control by deadlines and reduced decision quality may not be surprising to some readers, no other scholarship has taken up this question through empirical work. A trade-off between political control and decision quality might be expected under a range of theories in political science (e.g., Bawn 1995; Carpenter 2001, 2010; Huber and Shipan 2002; McCubbins, Noll, and Weingast 1987). Yet none of these theories

${ }^{2}$ We thank an anonymous reviewer for pointing out the rarity of this combination in empirical data, and for suggestive language.

${ }^{3}$ We can also think of deadlines as a tool of "performance management" (Blalock and Barnow 2001; Fossett, Gais, and Thompson 2001, 209).

${ }^{4}$ For example, see United States Senate $(2004,10)$.

${ }^{5}$ In addition, our sample covers a longer period than Carpenter, Zucker, and Avorn (2008). 
issues a straightforward prediction that imposition of control will lead to reduced decision quality on a salient dimension. Much of the literature on procedural control in fact seems to assume that its net effect is positive, preventing agencies from deviating from legislative intent. So too, it would be surprising to learn that the imposition of procedural control may not have advanced the interests of organized groups (or "stakeholders") who were most favorable to the change. However, despite the theoretical intuition behind the results, no study has yet provided empirical confirmation of a link between procedural control and the quality of regulatory outcomes. Our analyses also demonstrate that deadline control may have carried real, unanticipated losses for stakeholders - particularly patient advocate groups and perhaps drug companies themselves - who would have anticipated gains under the deadline policy. $<<$ heading 1 $>>$ Agency Time Discretion and Deadlines as Instruments of Political Control

For decades, scholarship has built on the insight that elected officials exercise control over government agencies through procedures that constrain agency discretion and incentivize agencies to craft policies beneficial to politically privileged interests (McCubbins, Noll, and Weingast 1989, 444). Classic examples include "making an agency rely on private interests for information, imposing tight deadlines...making certain types of decisions difficult to promulgate" and preventing agencies from collecting "information about the consequences of the policy decisions" (Bawn 1995, 63; McCubbins, Noll, and Weingast 1987, 1989; Moe 1989). Among these forms of prospective political control, deadlines represent "the most powerful, and arguably the most predictable, indirect mechanism of accountability at the disposal of Congress" (Kerwin 2003, 215-16). ${ }^{6}$

Deadlines share common features with other prospective procedural controls. Like other procedures, deadlines may shape the flow of information in and out of agencies in ways that bear on ultimate policy outcomes (Abbott 1987). Structuring the flow of information may constrain an agency's ability to apply its expertise and make bureaucrats responsive to certain interest groups (Balla and Wright 2001; McCubbins, Noll and Weingast 1987, 675). Deadlines may also impose penalties for failure while varying in their restrictiveness.

Deadlines differ from other tools of control in that they target a source of agency leeway-discretion on the time domain - for which other political control tools may be poorly equipped. A deadline can be shorter or longer; it can demand a decision or the completion of a task in three days or three years. The length of a deadline - the amount of elapsed time that it permits before the assignment of a penalty associated with being "late" or having "missed" the deadline - is associated with the discretion that it allows. From an organizational perspective, longer deadlines translate into greater agency discretion, as agency policy makers can engage in additional task search activities (e.g., information search, application of new or different technologies or heuristics to the task or decision). The longer time horizons embedded in longer deadlines may also protect slack resources from being inefficiently utilized when the agency is required to hurry to complete a large number of tasks in a short period of time. These slack resources may reduce the risk of committing decision errors (theoretically, for both the Type I and Type II varieties) attributable to politically induced time constraints on task performance.

Deadlines are widely prevalent in political and administrative settings. Statutory deadlines appear for a range of policy domains, ranging from environmental regulation (Morgenstern 1993) to traffic safety (Mashaw and Harfst 1990, 69-83). The 1988 amendments

${ }^{6}$ Kerwin argues untenable deadlines invite interest groups to pursue judicial review of agency decisions (Kerwin 2003, 215-16). 
to the Federal Insecticide, Fungicide and Rodenticide Act, for example, required the Environmental Protection Agency to re-register 700 substances within a period of 10 years (Morgenstern 1993, 245). ${ }^{7}$ In the field of pharmaceutical regulation, the FDA faces six-month deadlines for the review of therapeutically vital "priority" drugs and (since 1997) 10 months for most other drug reviews. Other health regulators worldwide including the European Medicines Evaluation Agency (EMEA) have adopted similar regulatory review deadlines. ${ }^{8}$ Moreover, a wide variety of administrative decisions are characterized by timing phenomena, including licensing (Kosnik 2006) and rulemaking (Kerwin 2003).

Scholarship has had less to say about how deadlines may impair the quality of agency decisions, potentially at the expense of the interests that political control intended to benefit. Some surveys suggest bureaucrats consider deadlines a weak form of Congressional oversight (Furlong 1998). Other studies report concern that deadlines limit bureaucrats' abilities to apply their expertise to policy decisions (HHS OIG 2003). With the exception of Gersen and O'Connell's (2008) hypotheses on the benefits and risks of congressionally imposed deadlines on agency behavior, we are unaware of any literature that tests how deadlines influence policy outcomes, or that empirically demonstrates when deadlines benefit intended constituents, as extant theory expects. ${ }^{9}$

$<<$ heading 1 $>>$ How Deadlines May Shape Decision Quality

Institutions based on deadlines shape agency behavior by attaching direct and indirect costs to agency decision making. The most direct form of deadline institution imposes a penalty (explicit or implicit) when a decision or administrative process runs beyond a specified point in time (the "deadline"). Where the deadline is absolute, this penalty may be conceived as "infinite" or large enough to outweigh all other factors in the regulator's decision, including factors ranging from the agency's possible risk aversion to the agency's reputation for decision quality and safety. In other cases, the deadline penalty may be smaller and one of plural factors to influence the timing of regulatory behavior.

Depending on those penalties, deadlines can affix costs to collecting and distributing information in the process of agency decision making, potentially affecting regulatory choice in at least two ways. They can influence the duration of decisions by preventing regulatory processes from elapsing beyond a certain time (the "timing effect"), and they can influence the quality of resulting decisions. ${ }^{10}$ By quality we mean both procedural quality (how well due

${ }^{7}$ Subsequent amendments imposed additional deadlines on the EPA's re-registration of pesticides even as they provided user fees to the agency (Schierow 2008, 8).

${ }^{8}$ Deadlines are proposed in other cases, such as visa issuance and customs. Business interests in the United States and Canada have been pressing for review-time goals for border crossing agents, and nonprofit groups have constructed an archive of border-time wait statistics to buttress these arguments.

${ }^{9}$ Scholarship on bureaucratic outputs has also largely neglected these issues. But see Olson (2008), Krause and Douglas (2006), Fershtman and Seidman (1993), and Gneezy et al. (2003), De Dreu (2003) and Huber and Kunz (2007).

${ }^{10}$ Consider an analogy from the scholastic realm. Suppose the a university dean instituted a rule requiring professors to spend no more than 30 minutes with a term paper before grading it. If professors previously spent no more than 15 minutes grading papers before the limit was imposed, it would be expected to have little if any effect. If on the other hand the usual professor spent one hour with each paper before grading it, we would be interested in whether the new 
diligence was exercised) and outcome quality (whether actual errors or harms resulted). This article empirically focuses on the latter, but also offers some suggestive evidence on the former. Deadlines may bear on outcome quality by limiting the time and resources a decision maker can apply to a policy decision. Of course, they cap the time that an agency has available to collect information and deliberate. In the process, deadlines may impair the amount of expertise an agency can mobilize or apply to a policy problem. Deadlines may also truncate agencies' efforts to communicate with external stakeholders and those implementing the agencies' decision. As implementers outside of the agency respond to this truncated communication, outcome quality changes in response.

Agencies face a dilemma balancing the costs of deadline violations against the information constraints, in part because different errors are differentially observable, and shortrun considerations may conflict with long-run considerations. Consider the possibility of a legislative deadline penalty that conditions agencies' future resource streams on meeting those deadlines. Deadlines, thus, may pit an agency's interest in using its expertise to produce accurate, valid decisions - and in protecting its long-run reputation for reliable expertise - against its interest in sufficient staff and funding and its short-run reputation for prompt action. Resource cuts are a certain, measurable, and quickly enforced punishment for agency failure to meet a deadline. And the failure to meet a deadline itself is easily observed. In contrast, the reputational and power costs resulting from lower-quality agency decisions are uncertain, poorly measured, and develop only over the long run, if at all.

Terms and Hypotheses. We use two novel terms in our analysis of deadlines' policy effects. A deadline regime is a policy that imposes decision time goals or rules upon an agency, with penalties for failing to meet the deadlines. It refers to years governed by a given piece of legislation. In contrast, deadline time $\left[t^{\text {dead }}\right]$, refers to the elapsed decision time after which the decision is regarded as late in a given regime. For a 90-day deadline, the deadline time is the $90^{\text {th }}$ day; for a nine-month deadline, the deadline time is the end of the ninth month.

In the presence of substantive penalties, we expect deadlines to alter both the timing and quality of agency decisions. Specifically, we expect that the introduction of a deadline regime will yield a greater likelihood of decision at the deadline time, $t^{\text {dead }}$, relative to:

- the predeadline time interval (time intervals before the deadline $t^{\text {dead }}-1, t^{\text {dead }}-2$ and so on).

- the postdeadline time interval (immediately following the deadline; $t^{\text {dead }}+1, t^{\text {dead }}+2$, and so on).

- the preregime deadline time (the deadline time intervals $\left[t^{\text {dead }}\right]$, but before a deadline regime was in place, or before there was a penalty associated with a decision after $t^{\text {dead }}$ ). Moreover, we expect the shift in the distribution of decisions will yield changes in outcomes. Specifically, we expect approvals that are completed at or just before a deadline to coincide with higher rates of revisitation (the agency correcting possible mistakes), error, and harm. ${ }^{11}$

$<<$ heading 1 $>>$ The FDA User-Fee Program and Review Deadlines: A Brief Description

deadline really did shorten the grading time (a timing effect), and in questions such as whether papers graded under deadlines offered less feedback or in other ways made students feel shortchanged (an outcome quality effect).

${ }^{11}$ Note, that the deadlines may still offer net benefits if they speed time-to-decision and reduce uncertainty sufficiently to outweigh the harms. 
The FDA deadline regimes offer an exemplary venue for testing our predictions and for laying the foundation for systematic understanding of deadline effects across government agencies and for ascertaining whether, in the process, deadline regimes benefit the intended interests. Unlike other policy domains where Congress may "hide its intentions" (Kerwin 2003, 214), the intended beneficiaries of FDA deadlines were clear: disease sufferers (especially the politically organized (Carpenter 2002)) and pharmaceutical firms (Hilts 2003, chaps. 16-18). Moreover, unlike other policy domains, drug approval provides reliable measures of decision quality. First, the FDA case offers important variation on our primary explanatory variable: deadlines. In the two decades before Congress passed the first FDA deadline regime, the Prescription Drug User Fee Act (PDUFA) of 1992 (which was subsequently reauthorized in 1997, 2002, and 2007), the FDA faced no time constraints on new drug application reviews. ${ }^{12}$ Intended to speed drug approval times, PDUFA represented a bargain struck between the FDA, Congress, and interest groups: user fees associated with PDUFA would augment FDA staffing resources while the pharmaceutical industry and concerned disease advocates would, in principle, receive quicker approvals and quicker access to new therapies. ${ }^{13}$ The deadline regime that PDUFA introduced is called a "review clock": upon a New Molecular Entity's (NME) initial submission date, a countdown timer begins ticking. The time on the clock (6 months, 10 months, or 12 months) differed according to whether the new drug application was designated "priority" or "standard.", 14

Among the features of the user-fee program relevant to FDA's approval behavior is the absoluteness of the review-clock deadline. Once the deadline has elapsed, the FDA's Center for Drug Evaluation and Research CDER has far less incentive to hurry a drug, as it no longer can count towards annual review-time goals. The provision that nine of ten drugs must be reviewed by the deadlines means that the PDUFA clock uniformly governs most all of FDA's drug review behavior. ${ }^{15}$ By imposing specific deadlines and linking agency compliance to the agency revenue source - the penalty for not meeting the deadline was not simply embarrassment and congressional pressure, but also the possibility that tens of millions of dollars in user fees would

${ }^{12}$ The 1997 reauthorization occurred as part of the Food and Drug Administration Modernization Act (FDAMA) of 1997.

${ }^{13}$ See testimony of Janet Woodcock, M.D., Acting Commissioner for Operations, FDA, Drug Safety and the Drug Approval Process, hearings before the Senate Committee on Health, Education, Labor and Pensions, March 3, 2005; http://www.hhs.gov/asl/testify/t050303b.html (accessed October 16, 2005). Employment in the Center for Drug Evaluation and Research increased from 1,041 in 1981 to 2,395 in 2005 . http://www.fda.gov/oc/oms/ofm/budget/2006/HTML/Summary/CDER.htm (accessed July 23, 2005).

${ }^{14}$ For review-time goals to be reached by FY 2002, see U.S. FDA, Office of the Commissioner, Office of Policy and Planning, "Report on PDUFA Goals: Original New Product Applications," http://www.fda.gov/oc/pdufa/report2002/2002-onpa.html (accessed October 16, 2005). For FY 99 goals and a summary of earlier deadlines and goals, see U.S. FDA, Office of the Commissioner, "Performance on FY 99 FDAMA Goals," http://www.fda.gov/oc/fdama/fdamaplnresponse/rptgoalsFY99.html (accessed October 16, 2005). time goals.

15 Since March and April 2008, the FDA has begun to relax its adherence to these review- 
no longer be available for personnel costs_-PDUFA represented a significant effort to influence FDA actions.

Applying our predictions to the FDA case, we expect that the deadline regime (PDUFA) will impose a meaningful constraint on drug review, prompting FDA to rush approvals in the months just before the deadline. Specifically, we expect the hazard of drug approval to be higher at $t^{\text {dead }}$ than in the months before $t^{\text {dead }}$ or the months after $t^{\text {dead }}$. Consider the 12 -month review clock for standard drugs, and suppose we focus attention on the agency's incentives to approve a drug in the next two months, however long the review has lasted to date. When the eleventh month of the review cycle starts, the incentives for completing NDA review in the next two months are high since near-term completion will allow the agency to meet the review clock for this drug. However, if the agency fails to meet the review-time goal, there should be less incentive to approve the drug in months 13 or 14 . Hence we should observe a high proportion of approvals concentrated or "piled up" in the months just before the deadline, and relatively few concentrated just after. The same logic should obtain regardless of the review clock length.

Moreover, we expect that drug approval decisions occurring just before the deadline time will be associated with safety problems in the postmarket period. Specifically, we hypothesize that drugs approved in the two-month window just before the deadline will express more markers of rushed decisions in the form of postmarket regulatory corrections and changes. ${ }^{16}$ While most drugs undergo some degree of regulatory modification in the postmarket period as they are prescribed to new patient groups, postmarketing regulatory events (PMREs) are a reliable measure of postmarket safety problems that might have been addressed at the drug-evaluation stage. PMREs include black-box (i.e., safety label) warnings, firm- and FDA-issued safety alerts, safety-based withdrawals, and market discontinuations of a (molecular) drug form.

$<<$ heading $1>>$ Deadlines and the Duration of Regulatory Review Cycle

Methods and Measures. To test our first set of hypotheses, that deadlines impose constraints by altering the timing of agency decisions such that the hazard of drug approval increases in the month the deadline elapses, we retrieve estimates of the conditional probability of approval at each point of the regulatory review cycle. At each month of the review cycle, what is the relative hazard rate of approval in the month, given that the drug has not yet been approved $?^{17}$ We conduct likelihood-based hazard analyses of review times and retrieve monthspecific hazard estimates that allow us to follow the pace of approvals during the FDA review cycle (Therneau and Gramsch 2000). To minimize dependence upon parametric statistical assumptions, we employ Cox proportional hazard models with time-varying covariates, including indicators for each month on the FDA review clock. Each model controls for staffing levels in the FDA's Center for Drug Evaluation and Research and includes indicators for the 50

${ }^{16}$ The online appendix includes results in which time windows other than two months are adopted. These alternative specifications - including a matching-based estimate that compares predeadline drugs to the comparable period in the pre-PDUFA era-corroborate the findings we present here.

${ }^{17}$ We do not include nonapproved drugs in our sample for two reasons. First, data on these drugs are not consistently available from the FDA. Second, systematically different incentive structures likely work on approvable and nonapprovable drugs; often a predeadline rejection simply throws work back upon the company sponsor and involves much less reputational risk for the FDA. 
largest firms. We estimate separate models for priority and standard drugs ${ }^{18}$ and use the Efron method for handling ties. ${ }^{19}$ (We reserve formal elaboration of our statistical models for the online appendix.) These models are applied to our sample consisting of New Molecular Entities (NMEs) approved between 1950 and 2008, for a total of 1,034 drugs.

Results. We hypothesized that deadlines induce drug approval "piling" in the months just before a deadline. We expected to find higher hazards in the month leading up to drug review deadlines. For standard drugs, the original PDUFA deadline was 12 months, changed to a 10month deadline after 1997 under the Food and Drug Administration Modernization Act (FDAMA). The postPDUFA deadline for priority drugs is six months.

[Table 1 and Figure 1 about here]

Our analyses suggest that deadlines have altered the timing of FDA decisions. Table 1 displays the hazard ratios for priority drugs submitted before and after the adoption of the sixmonth deadline regime. (These ratios are relative to the baseline condition when all covariates and indicators are set to zero. The baseline hazard encompasses all months for which monthregime dummies were not included.) For priority drugs submitted after the introduction of sixmonth PDUFA deadlines, we observe a sizable increase in approval hazards in the sixth month of the review: an eightfold increase in the hazard over the fourth month $\left(c^{2}=11.88 ; p=0.0006\right)$.

The hazard ratio drops nearly twelvefold in the eighth month, after the deadline has passed $\left(c^{2}\right.$ $=13.18 ; p=0.0003$ ). In contrast, in the period before the introduction of deadlines, the hazard ratio in the sixth month is significantly lower than in either the fourth or eighth months $\left(c^{2}\right.$ $=13.18 ; p=0.0003$ ). Figure 1 illustrates the monthly approval hazard ratios and accompanying $95 \%$ confidence intervals seen in Table 1, for the pre- and post-PDUFA periods. ${ }^{20}$ The confidence interval estimate of the deadline month in the post-PDUFA era appears in bold.

[Table 2 and Figure 2 about here]

These patterns generally apply to standard drugs as well. Table 2 contains the monthly approval hazard ratios retrieved from dynamic Cox estimation for the first 24 months of the review cycle for standard drugs. ${ }^{21}$ Figure 2 illustrates the monthly approval hazard ratios and accompanying 95\% confidence intervals seen in Table 2, for the pre-PDUFA, PDUFA, and FDAMA periods, with the confidence intervals of deadline-month estimates appearing in bold. For drugs submitted before 1993, no piling is observed around the tenth or twelfth months on the review clock. That is, for NMEs submitted before PDUFA, the approval hazard ratio for drugs in the tenth month was not statistically differentiable from that in the twelfth month $\left(c^{2}=0.05\right.$; $p=0.83$ ). Nor is the hazard for drugs approved in the twelfth month statistically differentiable from that in the fourteenth month $\left(c^{2}=2.37 ; p=0.12\right)$. The hazard for drugs approved in the tenth month is statistically differentiable from that in the eighth month $\left(c^{2}=6.68 ; p=0.01\right)$, but in the opposite direction: the hazard ratio is lower in the tenth month than in the eighth.

${ }^{18}$ A drug is deemed "priority" if "no satisfactory alternative therapy exists" or if it represents "a significant improvement compared to marketed products" (FDA 2007).

${ }^{19}$ Supplemental models add disease-specific frailties.

20 The horizontal axis is the number of clock months; the vertical axis is the hazard ratio in each month, relative to the baseline, presented on a logarithmic scale.

${ }^{21}$ Months 1-7 were included in the baseline because insufficient variation appeared in those months. 
For standard drugs submitted from 1993 to 1997 and thus falling under the provisions of PDUFA 1992, however, we observe a sizable increase in approval hazards for the twelfth month of review compared to the same month in the FDAMA regime (effective starting in 1997), when the deadline changed to 10 months $\left(c^{2}=5.73 ; p=0.02\right)$. Moreover, as hypothesized, approval hazards fall off appreciably for the month after the review clock deadline, comparing the twelfth month with the fourteenth $\left(c^{2}=6.69 ; p=0.01\right)$.

For the period since 1997, when the relevant deadline for standard NMEs has been 10 months, we indeed observe a large increase in approval hazards in the tenth month of the review cycle, compared with the tenth month under the previous twelve-month deadline regime $\left(c^{2}\right.$ $=8.22 ; p=0.004)$. Moreover, the approval hazard in the month before the ten-month FDAMA clock deadline elapses is two times greater than the approval hazard in the month after that review deadline elapses, though this increases does not approach standard levels of significance relative to the eleventh or twelfth month.

$<<$ heading $1>>$ Deadlines and Policy Outcomes

Our results above suggest that the introduction of deadlines has altered the timing of drug approvals. We now investigate whether the review clock institutions have influenced not just the timing, but also the quality of the FDA's decisions, particularly around drug safety and postmarketing regulatory issues. While some analysts have examined whether the overall rate of drug safety problems has changed since the introduction of deadlines, ${ }^{22}$ we compare the postmarketing experiences of drugs approved immediately before the deadline to those approved at other times in the review cycle, for NMEs approved after $1992 .{ }^{23}$

Measures of Postmarketing Regulatory Events. We examine four measures of postmarketing regulatory events. ${ }^{24}$ One is a dichotomous indicator of whether the approved drug later received a new postmarket black-box warning on its label for a significant new adverse drug reaction (ADR; Lasser et al. 2002). A second is a dichotomous indicator of whether an NME faced a safety-based withdrawal. A third measures FDA drug-specific safety alerts. These alerts include all safety-related letters, press releases, and health advisories circulated by the FDA and by pharmaceutical firms from 1996 through 2008, for all NMEs approved since 1996. We also examine a variable that is indirectly safety related: whether dosage-forms of the drug have been discontinued from the market place. Though discontinuation sometimes "indicates drugs that have been discontinued from marketing or that have had their approvals withdrawn for other than safety or efficacy reasons," that dosage withdrawal may be indirectly related to safety.

${ }^{22}$ M. Meadows, Why Drugs Get Pulled Off the Market. FDA Consumer 36 (1) (JanuaryFebruary 2002). L. D. Sasich, Comments before the Food and Drug Administration's Public Meeting on the Prescription Drug User Fee Act (PDUFA). September 15, 2000, (HRG Publication \#1536); URL: http://www.citizen.org/publications/print_release.cfm?ID=6737 [accessed December 22, 2005]; T. Moore, Psaty, B. M., Furberg, C. D. Time to Act on Drug Safety. JAMA, 279 (19) (1998):1571-73. Our measure also incorporates foreign withdrawals, e.g., Lexchin 2005.

${ }^{23}$ Only drugs approved after 1992 were potentially exposed to the "looming deadline" treatment.

${ }^{24}$ Descriptions of data used to create these outcome measures appear in our online appendix. 
When healthcare providers notice safety problems, clinical demand for a drug may decline. ${ }^{25}$ We report summary statistics in our online appendix.

Specification and Estimation of Generalized Linear Models. We use generalized linear models to estimate the implications of review deadlines on drug postmarketing experiences. For the sample of NMEs, we introduce one vector of parameters for estimation - a set of terms for each primary indication, or disease category (modeled as a random effect). Dozens (sometimes hundreds) of separate error terms or parameters are added to the models we estimate. This approach emulates some prior work on pharmaceutical policy (e.g., Carpenter 2002; Lasser 2002; Olson 1997, 2004), but our analysis includes a revised indexation of primary indications that accounts for substantively important distinctions between diseases. Other analysts control for generic therapeutic category terms (for example, for all cancer or central nervous system (CNS) drugs), but not for particular primary indications. Because primary indication largely governs drugs' assignments to CDER reviewing division, static factors associated with the division-level review organization are captured by this set of hundreds of terms.

We employ the generalized linear model (GLM) framework (McCullagh and Nelder 1989) for panel data and mixed effects models. (The online appendix contains more model details.) For each of the four postmarket event variables (black-box warning, safety-based withdrawal, safety alerts, and dosage discontinuation), we regress the regulatory event variable on the submission year (to capture the time trend), an indicator of whether the drug received approval within the two months before the deadline time (the key explanatory variable of interest), and selected other measures. We thus create the following variables:

1. Agency Decision Criteria: Predeadline Approval. We hypothesized that the piling of approvals near the deadline is associated with changes in drugs' postmarketing outcomes. Thus, for any deadline month and its preceding month $\left(t^{\text {dead }}, t^{\text {dead }}-1\right)$, we construct a "predeadline" approval indicator $Z^{P R E}$ scored 1 if the drug in question was approved in $t^{\text {dead }}$ or $t^{\text {dead }}-1$, and 0 otherwise. This represents our primary explanatory variable. Where the deadline is 12 months, for instance, approvals in the $11^{\text {th }}$ and $12^{\text {th }}$ month after submission are coded as 1 . This variable appears in Table 3 and Table A3 in the online appendix as "approved within two months of deadline."

2. Agency Uncertainty: Drug Priority and Novelty (Log Order of Drug Entry). To assess claims that lower-quality policy outcomes may arise from inherent drug uncertainty, we include two measures to capture agency uncertainty. One is an indicator of whether the FDA designated the drug for priority review, a designation reserved for drugs that represent significant innovation over existing therapies. Such innovation holds potential for greater drug safety and efficacy but greater uncertainty as new formulations are introduced into the market for the first time. The second measure accounts for drug novelty by taking the log of the number of drugs previously approved to treat the drug's primary indication. The more drugs to treat a particular disease, the greater experience the FDA may have with disease-specific therapies and the drug's performance in a well-known target population, while the FDA will have less prior information and more uncertainty around drugs targeting novel populations outside of the drug-trial setting. ${ }^{26}$

${ }^{25}$ In many cases, dosage discontinuation arises from weak clinical demand. See, e.g., "Dear Healthcare Professional" letter, September 2004. http://www.fda.gov/cder/drug/shortages/AgeneraseLetter_E2.pdf (accessed November 2, 2005).

${ }^{26}$ Fewer drugs on the market to treat a disease may also reflect patient demand for new therapies. 
3. Count of Previous Firm NME Approvals. To assess firm effects on drugs' postmarketing experiences and to test claims that postmarketing problems arise from established firms' relationship with regulators, we include a measure of firms' regulatory experience consisting of a count of the firm's previously approved NMEs at the time of submission.

[Table 3 about here]

Results: GLM Estimation. We report generalized linear model results for all NMEs approved between 1993 and 2007 in Table 3. Our measure of the deadline-induced change in FDA approval behavior - approval within two months of the deadline time-is positively and significantly related to new black-box warnings, safety-based withdrawals, and safety alerts, and positively though not significantly related to dosage form discontinuations. ${ }^{27}$

The results in the first columns for black-box warnings, safety-based withdrawals, and dosage discontinuations are logistic regression coefficients rather than readily interpreted quantities of interest. For this reason, the second column of results for these dependent variables reports the odds ratio for each covariate. We find that the probability of a drug approved in the two months before the deadline time receiving a new black-box warning is 3.27 times greater than a drug approved at some other time, according to the model specified for the NMEs approved between 1993 and 2007. For NMEs approved between 1993 and 2007, safety-based withdrawal is 6.92 times greater for a drug approved in the two months leading up to its approval deadline than for comparable drugs approved at other times. Drugs approved in the two months before a deadline were 1.54 times more likely incur a dosage form discontinuation, though again, this particular relationship is not significant at conventional levels. We also see a positive, significant relationship between approval within two months of deadline and safety alerts. There appears to be no stratification in the deadline effect across priority and nonpriority reviews, save for dosage-form discontinuations, where there is a deadline effect among standard drugs but not among priority drugs (see the online appendix, Tables A13a, b). The stratification of the deadline effect for dosage-form discontinuations suggests that we are not necessarily seeing a null result for this outcome variable as much as a conditioned result. That said, we have no a priori reason for having expected to see the difference observed here - though it may be due to the fact that voluntary dosage-form discontinuations are less likely for more profitable drugs. We believe that this is amenable to further investigation. On the whole, these results lend support to our argument that changes in the timing of FDA decisions - resulting in drug approval piling before the specified deadline - are associated with greater postmarketing regulatory events.

${ }^{27}$ The analyses in Table 3 are based on a dataset of 337 cases, chosen so as to standardize our sample across estimations presented in Table 3 and Table A3 in the online appendix. All were NMEs with submission years between 1993 and 2006. This is dataset was also used to creating the "matched" subdataset for the work reported in online appendix Table A3. In our online appendix (Tables A9, A10, A11, and A12), we report results based on a dataset of 342 cases; these estimates are substantively identical to those reported in the text and the main tables. The five-case difference owed to the need to prepare the dataset for the program used to produce matched data, MatchIt. Specifically, it was necessary to remove all cases which had missing data for one or more of the variables used in the analyses with generalized linear models. We report the $\mathrm{N}=337$ sample in Tables 3 (and A3) so as to present a consistent estimation sample across postmarket safety measures, yet we emphasize again that the substantive results are identical in the $\mathrm{N}=342$ sample (Tables A9-A12, online appendix). 
Supplemental Matching Analyses. We also seek to minimize the possibility that our results are dependent on modeling assumptions as a consequence of large differences between our implied treatment group (approval in the two months before a looming deadline) and our implied control group (drugs approved at other times). For a variety of reasons related to nonrandom assignment, these groups may not be equivalent in all relevant aspects except for the just-before-deadline approval. There is, to be sure, no way of eliminating omitted variables and other sources of bias as explanation for our results, which are generated from an observational research design. To at least reduce the likelihood that our results are due to baseline differences between the treatment and control groups, we match observations from the treatment and control groups on observables to construct a sample that allows estimation of the causal effect of the predeadline approval on the treated units that appear in the matched sample. Using two matching methods, optimal matching (Hansen 2004) and coarsened exact matching (Iacus, King, and Porro $2011),{ }^{28}$ we match on a range of covariates widely believed to predict predeadline approval. We then apply general linear models (without mixed effects) to account for any imbalance that may remain after matching (Ho et al. 2007). We examine issues of covariate balance and present results in the online appendix (Tables A1, A2, A3).

$<<$ heading 1 $>>$ Plausible Mechanisms: Timing and the Role of Outside Advice

Although we have not tested the hypothesis here, drugs approved in the window just before the deadline may be less likely to receive sufficient time and expertise applied to their reviews (Huber and Kunz 2007), perhaps through curtailed advisory committee consultations or rushed drug labeling decisions, which typically occur at the end of the review process. Given the certain publicity that accompanies tardiness in drug approval, relative to the uncertainty over whether rushed approvals will yield reputational damage, we suspect that incentives to meet the deadlines may outweigh reputational and other considerations that contribute to decision quality (see also Krause and Corder 2007).

From the perspective of some anonymous FDA staffers, this is what happened after the introduction of deadlines. A 2003 Office of Inspector General survey reported agency concerns about insufficient time to review and debate drug applications. Staffers' concerns focused on the end of the review cycle, when the agency convenes with its public advisors about challenging applications and labeling decisions. FDA staffers and OIG inspectors both expressed concern that deadlines impaired the agency's ability to consult with advisors and encouraged the agency to "rush to finalize drug labels at the end of the process" (HHS OIG 2003, 6) ${ }^{29}$ Drug labels contain "key information concerning...safe and effective use" including drug warnings and contraindications (HHS OIG 2003, 27). Advisory committees provide the FDA with expertise for drug approval and labeling decisions, and they represent important venues for communicating

${ }^{28}$ Optimal matching has the advantage of generally using a larger fraction of observations in the analysis and has other desirable properties relative to nearest-neighbor propensity-score matching. Coarsened exact matching (CEM), places covariates in multivariate bins of varying dimensions. Observations in either the treatment or control group are discarded if observations with the opposite treatment status do not appear in the same bin. While this method produces inferences about an undefined and unknowable target population, it potentially provides better balance when treated and control observations cannot be matched easily.

${ }^{29}$ The Inspector General also reported significant constraints on the FDA's ability to shift internal staff resources to address workload demands (HHS OIG 2003, iv). 
potential drug risks to broader audiences (Moffitt 2010). ${ }^{30}$ In its "rush," the agency may have lost key methods to improve drug safety messages and their conveyance.

We find preliminary descriptive evidence that activities such as advisory committee reviews received less attention after the introduction of deadlines (Our results appear in Table A4 in our online appendix). Using a sample of drugs approved between 1986 and 2006, we found that deadline regime drugs were significantly less likely to experience advisory committee reviews prior to the drugs' approval compared with drugs that did not face deadlines. ${ }^{31}$ Our results also suggest that drugs approved in the deadline window were less likely to receive an advisory committee review compared with drugs approved at all other points in the process, though there is more uncertainty associated with this estimate. The relationship between looming deadlines and advisory committee reviews achieves standard levels of statistical significance in only one of our two models.

Implications. We have adduced evidence for the hypothesis that at-deadline approvals are more likely to be withdrawn from the marketplace, are more likely to receive safety alerts, and are associated with a higher rate of postapproval black-box warnings. Whether these regulatory indicators are indicative of real human and economic costs is another question. This question is one whose ultimate scope demands a separate article. In the interest of demonstrating that serious, unanticipated consequences to deadlines may have exacted tangible costs on the some of the supporters of the deadline regime (e.g., patient advocates) we offer a brief overview of the plausible human health correlates of postmarket safety problems. If the average drug withdrawal is associated with 50,000 deaths, say, then a small increase in the probability of a drug withdrawal may be expressive of an appreciable number of lives lost or damaged. Using a supplemental database of all reported adverse drug reactions from 1996 to 2006, we estimate the average change in reported adverse drug events associated with two of our postmarket regulatory outcomes - drug withdrawals and safety alerts.

This database, collected from the FDA's MEDWATCH system, ${ }^{32}$ classifies drug adverse events into a number of categories, but three are of interest here: (1) adverse events associated with a patient's subsequent death, (2) adverse events associated with a patient's subsequent hospitalization, and (3) adverse events associated with a patient's subsequent disability. Each safety-based drug withdrawal is associated with 29,741 additional adverse events associated with death, 160,993 additional adverse drug events associated with hospitalization, and 14,217 additional adverse events associated with a reported disability. If we take a one-unit shift in the natural logarithm of safety alerts as a predictor, such a change predicts 13,321 more death-related adverse events, 44,306 hospitalization-related adverse events, and 6,953 disability-related adverse drug reactions.

For a number of reasons, these numbers must be taken as suggestive only of possibly correlated effects of safety-based withdrawals and safety alerts. One problem is that there is massive underreporting of adverse events, such that many pharmacologists and drug safety

${ }^{30}$ In a sample of 26 advisory committee meetings convened in 2008 to review NMEs, all of the meetings contained discussion of drug labels; and that discussion was cursory only twice.

${ }^{31}$ This finding is consistent with Moffitt (2010).

${ }^{32}$ It is often argued that data culled from the MEDWATCH system is subject to significant underreporting, which may yield a very conservative sample of safety issues associated with an FDA-approved drug. We have no way of correcting for this possible reporting bias but note it here as a reason for circumspection about our analyses. 
experts see them as only indicative of drug safety problems. Another problem is that one can never be certain that a drug caused a death or hospitalization in a given case; the MEDWATCH system is based upon reporting of physicians' and manufacturers' suspected associations of an adverse event with use of a particular drug. For this reason, we do not attempt here to causally tie at-deadline approvals to higher rates of adverse events. These correlates, however, do suggest that postmarketing regulatory events such as drug withdrawals and safety alerts reflect tangible and appreciable human costs; they are correlated with induced hospitalizations, induced disabilities and deaths.

$<<$ heading $1>>$ Discussion

Agencies have significant time discretion in their operations and decisions. For this reason, deadlines embedded in rules and legislation represent a potent form of political control. Our empirical results suggest that in the area of U.S. pharmaceutical regulation, deadlines influence the timing of agency decisions, resulting in the piling of drug approvals right before the deadline. Moreover, drugs approved right before the deadline are associated with more safety problems when reaching the market. Rushing approvals at the end of the review cycle may, we argue, be the mechanism behind this association, compromising the agency's ability to gather and distribute information through public advisory committees and through careful drug labels, information that is vital to safe and effective drug use on the market.

Our argument departs from traditional theories of political control in several ways. First and foremost, we focus on the time domain of agency discretion, and not (as much) on the kind of ideological or nontime performance metrics examined in previous literature. Our arguments are not about the overall quality of the products being regulated, an argument that might fit more neatly into existing research in the political control literature. We instead argue that the specific behavior change induced by the deadline - approval piling right before the deadline-is associated with specific changes in the quality of policy outcomes as captured by postmarketing regulatory events for drugs approved right before the deadline. The trade-off between political control and expertise must account for potential damage to the interests that political control intended to benefit: damage that arises when agency expertise is impaired through political control.

Our results are not uniform, as they vary slightly depending on model specification (hence our reporting of multiple specifications of the GLMs and robustness checks reported in the online appendix including different matching specifications). However, we observed no statistically significant negative relationships between deadline approvals and postmarketing regulatory events (PMREs) across all of the robustness checks done on the results reported here. Moreover, we $d o$ observe a large number of positive relationships statistically significant at the 5\% level between deadline approvals and PMREs that hold across statistical specifications. While detection methods for adverse postmarket events and other safety issues have improved in the past two decades, the starkness of the deadline effects observed here suggests that broader trends in pharmacoepidemiology are unlikely to have contributed to the positive association between approval under a looming deadline and adverse postmarket events.

Our model estimates offer appreciable evidence that political control through regulatory deadlines affects the timing and quality of agency decisions. We thus offer important theoretical and empirical extensions to political control scholarship that predicts a trade-off between political control and agency expertise. Procedural controls that constrain expertise can produce outcomes that adversely affect intended beneficiaries. While we agree that Congress' motive in promulgating controls is often specifically to "enfranchise some groups and exclude others" or to 
delimit "who has access to the agency" (Bawn 1995, 62), the winners and losers in the story we present are not as straightforward as a stylized model might imply. Though disease sufferers were the intended beneficiaries of the FDA deadline regime, they may bear the unintended costs of rushed approval in the form of unanticipated safety problems. One AIDS advocate, looking back on the FDA's acceleration, lamented that "We have arrived in hell...AIDS activists and government regulators have worked together, with the best intentions, over the years to speed access to drugs. What we have done, however, is to unleash drugs with well-documented toxicities onto the market, without obtaining rigorous data on their clinical efficacy" (Hilts 2003, 251). While the disappointed AIDS activist does not mention deadlines directly, it is clear from our estimates that these deadlines have been part of the acceleration. The activist points clearly, moreover, to the foregone informational benefits of quicker FDA decisions. So too, it is quite possible that drug firms whose safety problems have been resulting in lower sales and increased public distrust might question the gains they have received from deadlines (Berenson 2005). The net benefits of deadlines may still have been positive, but it is clear that not all of the costs would have been anticipable, as current theories of administrative procedures assume.

The mechanisms through which deadlines impair decision making-limiting the amount of time and information an agency may bring to bear on decisions, limiting conveyance of political information to the agency, restructuring agency decision criteria-manifest in other forms of political control. Appointments, for instance, can change the information an agency has at its disposal as well as alter the agency's criteria and culture. Budgets, for their part, embody concrete resources and political symbols. The fundamental similarity in the mechanisms that enable instruments of political control give us confidence that our deadline results apply broadly to other institutions designed to shape and constrain bureaucratic behavior.

Our findings also offer useful implications for the study of drugs and other regulators. We have focused the present analysis upon new molecular drug approval in the United States, but drug reviews at the European Medicines Evaluation Agency (EMEA) are also governed by a system of review-time deadlines, as are thousands of other FDA reviews not analyzed here (of medical devices, biologic drugs and generic drugs, among others). There are, furthermore, many administrative and regulatory decisions outside drug regulation characterized by timing phenomena (O'Connell and Gerson 2008; Yackee and Yackee 2010). Wherever deadlines apply to administrative timing processes, our models will be of potential analytic value.

Though we find consistent results under the FDA deadline regime, future research should consider two additional aspects of agency learning. First, when agencies develop a reputation for meeting the "spirit" of the deadline (i.e., getting therapies on the market more quickly), are they better able to violate the specific terms of the deadline without political consequence? As agencies and political overseers demonstrate timeliness, in other words, do deadlines become less "absolute?" Second, as agencies adapt to deadline regimes, do they learn how to adjust their work processes to afford both quality and timeliness? If so, how and by what procedural and organizational mechanisms? These future lines of inquiry will help illuminate the durability of deadline institutions and their consequences.

Considerable scholarship over the past 30 years has explored the range of tools elected officials have applied to shape bureaucratic behavior and constrain discretion, but it has largely ignored the time dimension of discretion and has attended much less systematically to the consequences of such political control. Our study offers an important contribution to this ongoing discussion by demonstrating how deadlines influence the quality of agency decisions by constraining an agency's time discretion. 
$<<$ REF $>>$ References

Abbott, Alden. 1987. "Case Studies on the Costs of Federal Statutory and Judicial Deadlines." Administrative Law Review 39: 467-87.

Ando, Amy Whitenour. 1999. "Waiting to be Protected under the Endangered Species Act: The Political Economy of Regulatory Delay." Journal of Law and Economics 42 (1): 29-60.

Balla, Steven J., and John R. Wright. 2001. "Interest Groups, Advisory Committees, and Congressional Control of the Bureaucracy." American Journal of Political Science 45 (4): 799-812.

Bawn, Kathleen. 1995. "Political Control versus Expertise: Congressional Choices about Administrative Procedures." American Political Science Review 89 (1): 62-73.

Berenson, Alex. 2005. "Big Drug Makers See Sales Decline with Their Image." New York Times, November 14, 2005.

Blalock, Ann B., and Burt S. Barnow. 2001. "Is the New Obsession with Performance Management Masking the Truth about Social Programs?” In Quicker, Better, Cheaper? Managing Performance in American Government, ed. Dall W. Forsythe. New York: The Rockefeller Institute Press, 485-517.

Carpenter, Daniel P. 1996. "Adaptive Signal Processing, Hierarchy, and Budgetary Control in Federal Regulation.” American Political Science Review 90 (2): 283-302.

Carpenter, Daniel P. 2001. The Forging of Bureaucratic Autonomy: Reputations, Networks, and Policy Innovation in Executive Agencies, 1862-1928. Princeton, NJ: Princeton University Press.

Carpenter, Daniel P. 2002. "Groups, the Media, Agency Waiting Costs, and FDA Drug Approval." American Journal of Political Science 46 (3): 490-505.

Carpenter, Daniel P. 2004. "Protection without Capture: Product Approval by a Politically Responsive, Learning Regulator," American Political Science Review 98 (4) (November) 613-31.

Carpenter, Daniel P., Evan James Zucker, and Jerry Avorn. 2008. "Drug-Review Deadlines and Safety Problems." New England Journal of Medicine 358 (13): 1354-61.

Carpenter, Daniel. P. 2010. Reputation and Power: Organizational Image and Pharmaceutical Regulation in the FDA. Princeton, NJ: Princeton University Press.

De Dreu, Carsten. K. W. 2003. "Time Pressure and the Closing of the Mind in Negotiation," Organizational Behavior and Human Decision Processes, 91 (2): 280-295.

Fershtman, Chaim, and Daniel Seidmann. 1993. "Deadline Effects and Inefficient Delay in Bargaining with Endogenous Commitment." Journal of Economic Theory 60: 306-21.

Food and Drug Administration. 2007. Manual of Policies and Procedures: Center for Drug Evaluation and Research. MAPP 6020.3.

Fossett, James, Thomas Gais, and Frank J. Thompson. 2001. "Federalism and Performance Management: Health Insurance, Food Stamps, and the Take-Up Challenge.” In Quicker, Better, Cheaper? Managing Performance in American Government, ed. Dall W. Forsythe. New York: The Rockefeller Institute Press, 207-44.

Furlong, Scott R. 1998. "Political Influence on the Bureaucracy: The Bureaucracy Speaks." Journal of Public Administration Research and Theory 8 (1): 39-65.

Gersen, Jacob, and Anne O'Connell. 2008. "Deadlines in Administrative Law." University of Pennsylvania Law Review 156: 923.

Gneezy, Uri, et al. 2003. "Bargaining Under a Deadline: Evidence from the Reverse Ultimatum Game." Games and Economic Behavior 45: 347. <<AU, provide issue number $>>$ 
Hansen, Ben B. 2004. "Full Matching in an Observational Study of Coaching for the SAT." Journal of the American Statistical Association 99 (467) : 609-18.

Ho, Daniel, Kosuke Imai, Gary King, and Elisabeth Stuart. 2007. "Matching as Nonparametric Preprocessing to Reduce Model Dependence in Parametric Causal Inference." Political Analysis 15: 199-236.

Hilts, Philip J. 2003. Protecting America's Health: The FDA, Business and One Hundred Years of Regulation. New York: Alfred Knopf.

Huber, John, and Charles R. Shipan. 2002. Deliberate Discretion: The Institutional Foundations of Bureaucratic Autonomy. New York: Cambridge University Press.

Huber, Oswald, and Urs Kunz. 2007. "Time Pressure in Risky Decision-making: Effect on Risk Defusing." Psychology Science 49 (4): 415-26.

Iacus, Stefano, Gary King, and Giuseppe Porro. 2011. Multivariate Matching Methods That Are Monotonic Imbalance Bounding. Journal of the American Statistical Association 106 (493): 345-61.

Kerwin, Cornelius. 2003. Rulemaking: How Government Agencies Write Law and Make Policy. Washington, DC: CQ Press.

Kosnik, Lea-Rachel D. 2006. "Sources of Bureaucratic Delay: A Case Study of FERC Dam Relicensing." Journal of Law, Economics and Organization 22 (1): 258-88.

Krause, George A. 2003. "Coping with Uncertainty: Analyzing Risk Propensities of SEC Budgetary Decisions, 1949-97." American Political Science Review 97 (1): 171-88.

Krause, George A., and J. Kevin Corder. 2007. "Explaining Bureaucratic Optimism: Theory and Evidence from U.S. Executive Agency Macroeconomic Forecasts." American Political Science Review 101 (1): 129-42.

Krause, George A., and James W. Douglas. 2006. "Does Agency Competition Improve the Quality of Policy Analysis? Evidence from OMB and CBO Fiscal Projections." Journal of Policy Analysis and Management 25 (1): 53-74.

Lasser, Karen E., Paul D. Allen, Steffie J. Woolhandler, David U. Himmelstein, Sidney M. Wolfe, and David H. Bor. 2002."Timing of New Black Box Warnings and Withdrawals for Prescription Medications." Journal of the American Medical Association 287 (17): 2215-20.

Lewis, David E. 2008. The Politics of Presidential Appointments: Political Control and Bureaucratic Performance. Princeton, NJ: Princeton University Press.

Lexchin, Joel. 2005. "Drug Withdrawals from the Canadian Market for Safety Reasons, 19632004." Canadian Medical Association Journal 172 (6): 765-67.

Mashaw, Jerry, and David Harfst. 1990. The Struggle for Auto Safety. Cambridge, MA: Harvard University Press.

McCullagh, Peter, and J. A. Nelder. 1989. Generalized Linear Models. London: Chapman and Hall.

McCubbins, Mathew D., Roger G. Noll, and Barry R. Weingast. 1987. "Administrative Procedures as Instruments of Political Control." Journal of Law, Economics, \& Organization 3 (2): 243-77.

McCubbins, Mathew D., Roger G. Noll, and Barry R. Weingast. 1989. Structure and Process: Administrative Arrangements and the Political Control of Agencies. Virginia Law Review 75 (2): 431-82.

Moe, Terry M. 1985. "Control and Feedback in Economic Regulation: The Case of the NLRB." American Political Science Review 79 (4): 1094-1116. 
Moffitt, Susan L. 2010. "Promoting Agency Reputation through Public Advice: Advisory Committee Use in the FDA." Journal of Politics 72 (3): 880-93.

Morgenstern, Richard. 1993. "Science, Engineering, and Regulation." In Keeping Pace with Science and Engineering, Myron F. Uman, ed. Washington, DC: National Academic Press, 243-50.

Nardinelli, Clark, Michael Lanthier, and Robert Temple; Daniel Carpenter. 2008. "Drug Review Deadlines and Safety Problems [Correspondence]." New England Journal of Medicine 359 95-98.

Olson, Mary K. 1997. "Firm Characteristics and the Speed of FDA Approval." Journal of Economics and Management Strategy 6: 377-401.

Olson, Mary K. 2004. "Managing Delegation in the FDA: Reducing Delay in New-Drug Review." Journal of Health Politics, Policy, and Law 29 (3): 397-430.

Olson, Mary K. 2008. "The Risk We Bear: The Effects of Review Speed and Industry User Fees on New Drug Safety." Journal of Health Economics 27 (2): 175-200.

Schierow, Linda-Jo. 2008. "Pesticide Law: A Summary of the Statutes," (Washington, DC: Congressional Research Service).

Spence, David B. 1999. "Managing Delegation Ex Ante: Using Law to Steer Administrative Agencies." Journal of Legal Studies 28 (2): 413-59.

Therneau, Terry M., and Patricia M. Grambsch. 2000. Modeling Survival Data: Extending the Cox Model. New York: Springer-Verlag.

Ting, Michael M. 2001. "The 'Power of the Purse' and Its Implications for Bureaucratic Decision Making." Public Choice 106 (3-4): 243-74.

United States Department of Health and Human Services Office of the Inspector General. 2003. FDA Review Process for New Drug Applications. OEI-01-01-00590. Washington, DC: Department of Health and Human Services.

United States Senate. 2004. November 18. "FDA, Merck, and Vioxx: Putting Patient Safety First?"

Hearing before the Committee on Finance.

Weingast, Barry R. 1984. "The Congressional-Bureaucratic System: A Principal-Agent Perspective (with applications to the SEC)." Public Choice 44 (1984): 147-91.

Whitford, Andrew B. 2005. "The Pursuit of Political Control by Multiple Principles." The Journal of Politics 67 (1): 29-49.

Yackee, Jason Webb, and Susan Webb Yackee. 2010. "Administrative Procedures and Bureaucratic Performance: Is Federal Rule-Making 'Ossified'?” Journal of Public Administration Research and Theory 20 (2): 1-22. 